\title{
GREEK GRAFFITI FROM DER EL BAHARI AND EL KAB.
}

THE following inscriptions were copied during the winter of 1897-8: those from the temple of Der el Bahari in November and December; those from the neighbourhood of El Kab in February, 1898.

DER EL BAHARI. ${ }^{1-T}$ The funerary temple of Queen Hatshepsut of the XVIIIth Dynasty, dedicated in honour of Amen Ra, and now known as Der el Bahari, stands on the western side of the Nile valley, under the eastern cliffs of the limestone ridge which separates the valley of the tombs of the kings from the great Theban cemetery which stretches from Goornah to Medinet Habou. The temple is laid out at three levels, having an entrance court on the lowest level, from which there is access by a central incline to a second or middle court, and this leads to a third or upper court, whose western and northern sides are built against the cliffs in which the sanctuary is excavated. All the graffiti given here (Fig. 1) come from the Eastern and Southern walls of this upper court. They are noted in the order they occur, on the Eastern wall from N. to S., on the Southern wall from E. to W.

Eastern wall. E. face. S. of the central granite doorway. On dado line.

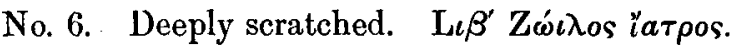

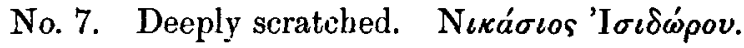

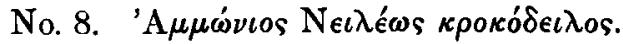

The third word is very lightly scratched, and is obviously an addition by some humorist.

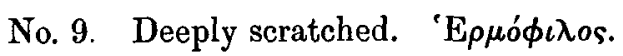

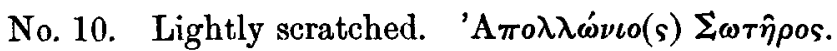

Lightly scratched. 'A

In the two last the patronymics are worthy of note. 'Е $\rho \mu \circ \kappa \lambda \epsilon i o s$ is

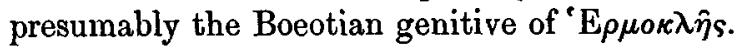

\footnotetext{
1 See the publications of the Egypt Exploration Fund on Deir-el-Bahari, Nos. XIl., XIII. XIV., and XVI.
} 
C. R. PEERS.

Eastern wall. W. face. N. of central doorway.

No. 5. On dado line. Very lightly scratched with a fine point.

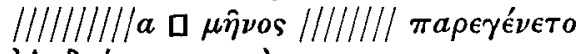

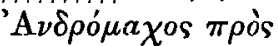

Unfinished. The first word is probably $\dot{\eta} \mu e^{\prime} \rho$, , followed by a numeral.

S. of the central doorway.

No. 4. Immediately below dado line. Lightly scratched. $72 \mathrm{~cm}$. from jamb of doorway. Kapoíuapos.

No. 3. On dado line. On course next to $N$. of the two following graffiti. Scratched. "Aגeos.

No. 2. On dado line. "A $\lambda \epsilon \iota$ s.

No. 1. On dado line, below preceding, very lightly scratched, and

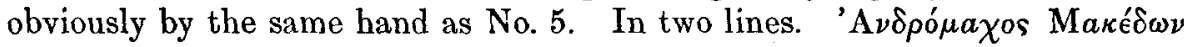

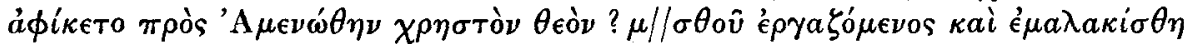

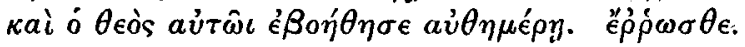

For the reading of the eighth word I am indebted to Mr. G. F. Hill, to whom also I owe the note on Amenothes printed below. There is no sign of an $\iota$ in the original, but $\mu \iota \sigma \theta a v$ seems the word demanded by the sense. letters.

Below this inscription is the name 'A $\nu \delta \rho$ of os scratched in large

Southern wall. $\quad$ N. face.

No. 11 . $30 \mathrm{~cm}$. below dado line. $2 \cdot 36$ west of the middle doorway of three in this wall, roughly cut with a chisel-edged tool. The last word scratched only.

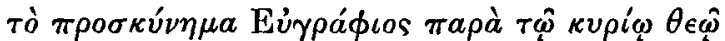

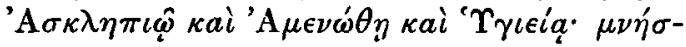

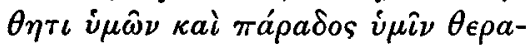

$$
\begin{aligned}
& \pi \epsilon i a \nu
\end{aligned}
$$

Added to the original inscription, below.

$$
\begin{aligned}
& \kappa a \grave{\phi} \phi \iota \tau \omega \beta \\
& \sigma \nu \nu \beta o \eta \theta o u ́ \nu \tau \omega \nu . . \chi \chi € \rho \tau a \pi a \nu \epsilon ? \\
& \pi \in \sigma \nu \beta \iota \varsigma
\end{aligned}
$$

Above :-

$\epsilon i s \theta \epsilon \dot{s}$ ó $\beta o \eta \theta \hat{\omega} \nu \dot{v} \mu \hat{\omega} \nu$

followed by an 'ankh' cross with palms. Below the main inscription, to the left, is a similar cross, and another of different form.

The latter addition with the crosses seems to be a commentary by a Christian convert on the original inscription. 


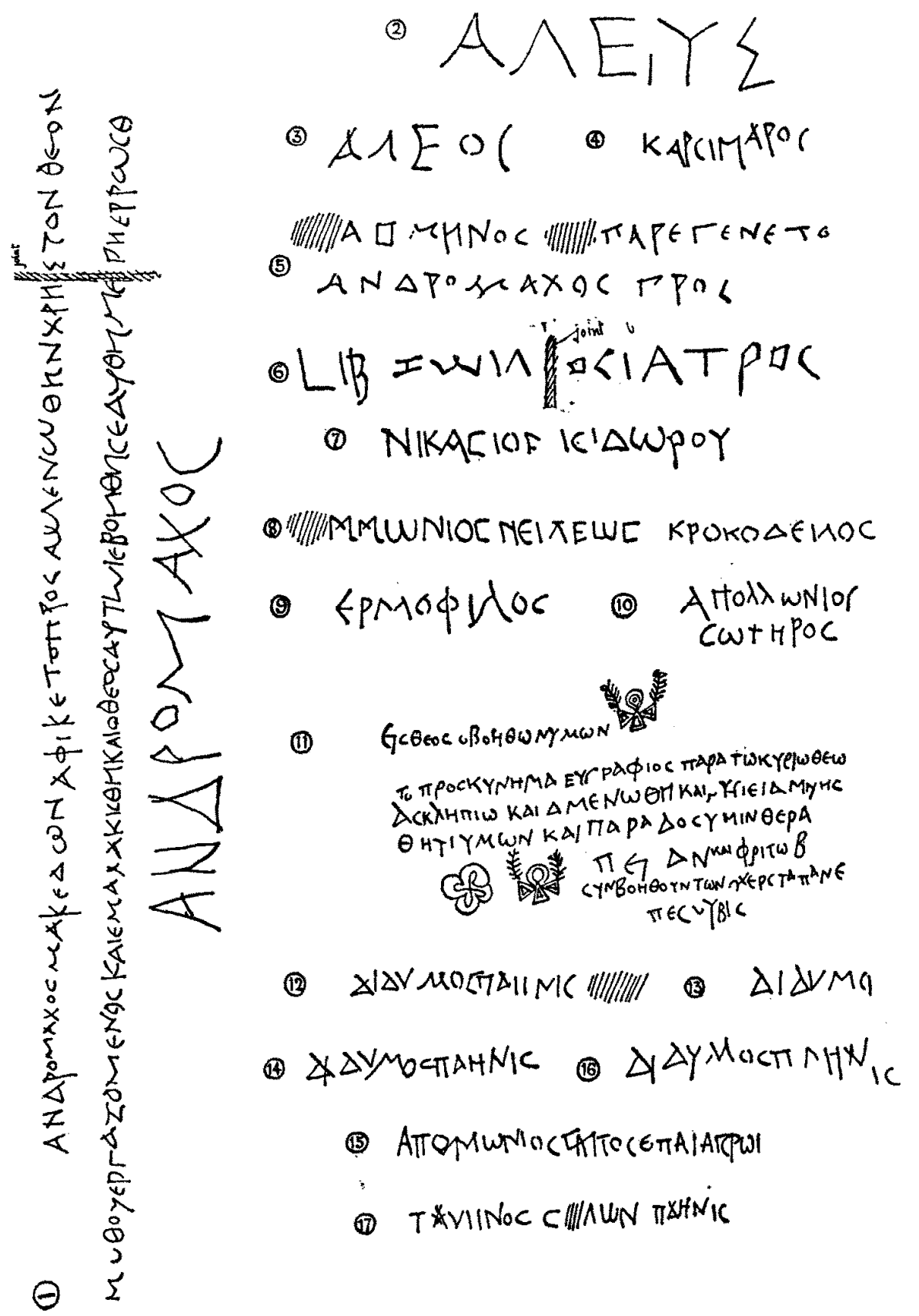

Fig. 1. Graffiti from Der el Bahart. 
In the main inscription $\dot{v} \mu \hat{\omega} \nu, \dot{v} \mu \hat{\imath} \nu$ are for $\dot{\eta} \mu \hat{\omega} \nu, \dot{\eta} \mu \hat{\imath} \nu$, as often.

Amenothes is presumably not Amenhotep III., but the wise man Amenhotep, son of Hapu, the contemporary of the king his namesake. Wilcken has published ${ }^{1}$ an ostrakon of the third century B.C., found at Der el Bahari, and containing a set of maxims ( $\dot{v} \pi \circ \theta \hat{\eta} \kappa a \iota)$ attributed to 'A $\mu \epsilon \nu \omega \dot{\tau} \eta \bar{s}$. As Wilcken shows, the maxims are really of Greek origin. In Ptolemaic times Amenhotep was worshipped in association with the god Imhotep, who corresponds to Asklepios, at the temples of Der-el-Medineh, Medinet-Habu, and Der-el-Bahari. ${ }^{2}$ The three representations of Amenhotep as a deity all belong to about the time of Ptolemy Euergetes II. A papyrus (Bulak No. 3), in which Amenbotep is also associated with Imhotep, belongs, according to Sethe, to late Ptolemaic times. Manetho (Josephus c. Ap. i. 232, 236, 243)

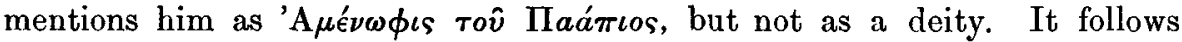
therefore that he was deified in Ptolemaic times, probably first under Euergetes II. To this time (c. 170 B.c.) our graffito may very well belong.

The latter part of the inscription and the added words after Aepanciav appear to be composed of fragments of magical formulae.

No. 12. On top line of dado. Next course to W. of preceding.

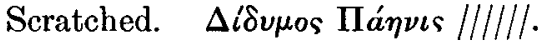

This name occurs in three other places on this wall (Nos. 13-16).

No. 15. $77 \mathrm{~cm}$. above dado and $5.25 \mathrm{~W}$. of preceding. Lightly scratched. 'A $\pi \circ \lambda \lambda \omega \dot{\nu} \iota \circ$ s...

The word following 'A

No. 17. Below dado. 1.75 E. of jamb of western doorway in this wall.

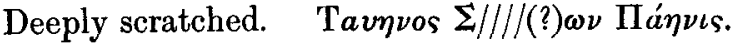

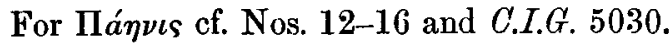

EL KAB.-On the walls of the forecourt of the little Ptolemaic temple of Eileithyia, in the eastern desert behind $\mathrm{El} \mathrm{Kab}$, are a number of unimportant graffiti, often consisting of a few letters only. I give here (Fig. 2) a few, which (with the exception of C.I.G. $4835 \mathrm{~b}$, which I did not find) are the only ones worth recording. Facsimiles of Nos. 1, 3, and 5 have been published by Petrie, $A$ Season in Egypt, Pl. XVII. Nos. 643, 644, 648.

Gateway of forecourt, eastern pier, outer face, on third course from ground.

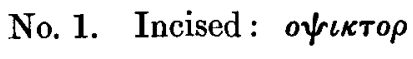

$a \pi i s$

No. 2. Below preceding; scratched : $\Delta \rho a ́ \kappa \omega \nu$

\footnotetext{
1 Aegyptiaca: Festschr. für G. Ebers, p. $142 \mathrm{f}$. I owe this and the succeeding reference

on this subject to Mr. F. Ll. Griffith.

2 Acgyptiaca, p. 106 f. (K. Sethe.)
} 
GREEK GRAFFITI FROM DER EL BAHARI AND EL KAB. 17 $\Sigma \mu i \theta_{\iota \nu}$.

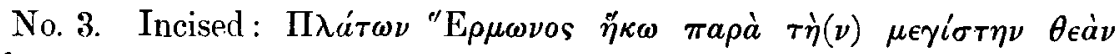

Already published in C.I.G. iii. 4835, and Petrie, l.c.

The above three inscriptions occur on the stone in the same relative position as is indicated in the illustration.

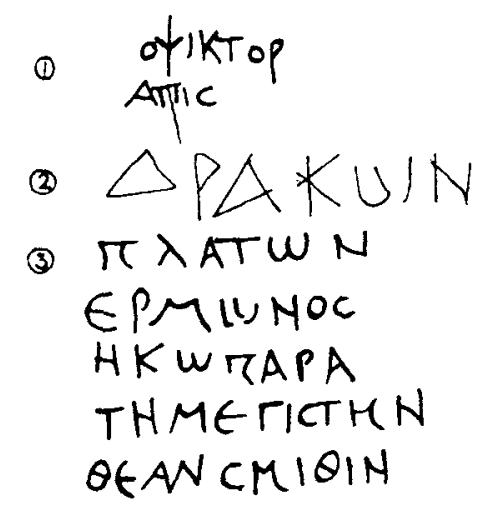

(4) $\lambda 04 \times 100$

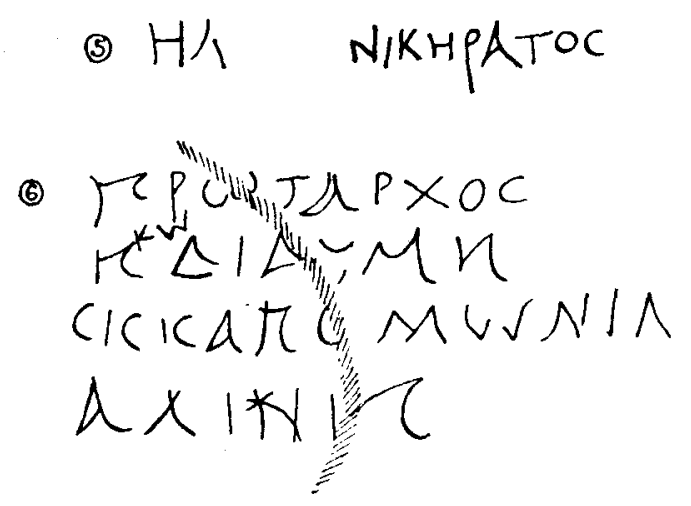

Fig. 2.-Grafeiti frou El has.

Western pier, outer face, on third course from ground;

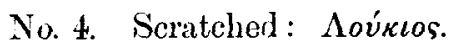

On western wall of forecuurt, inner face, second bay from entrance, on third course.

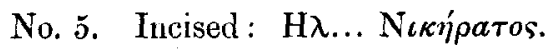

Five minutes to the west of the Eileithyia temple, following the line of the cliffs bounding the valley, on the western side of the mouth of a small

H.S.-VOL, XIX. 


\section{GREEK GRAFFITI FROM DER EL BAHARI AND EL KAB.}

khor, and at the foot of an anciently quarried cliff, is a large sandstone boulder, with a flat upper surface, on which is scratched the following inscription. The boulder has been cracked across since the writing of the inscription, and the pieces have fallen apart, making a break through all four lines.

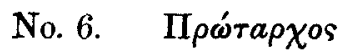

$\eta \tilde{\kappa} \kappa \omega \Delta \iota \delta \dot{u} \mu \eta$

? $\sigma \iota \sigma \iota \sigma a \pi o \lambda \lambda \omega \nu \iota \delta$ ?

'A $\lambda i \nu \eta$

The first and last letters of 1.3 are doubtful; they may be $\varepsilon$ and $\lambda$ or $a$.

Ll. 3 and 4 are not clear. The inscription may refer to the goddess to whom the neighbouring temple was dedicated, and who is called Smithis in

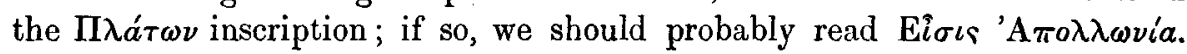
But as this title is not otherwise known it is safer to assume that we have here a string of names.

C. R. Peers. 